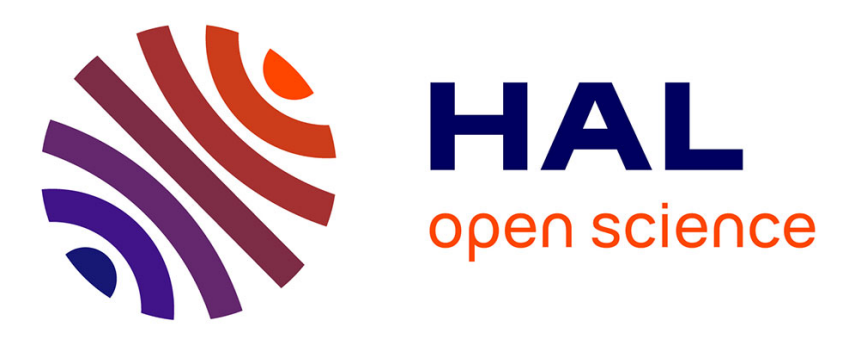

\title{
Divided Together: How Marginalization of Intercultural Relationships Is Associated With Identity Integration and Relationship Quality
}

Maya A Yampolsky, Alexandria L West, Biru Zhou, Amy Muise, Richard N Lalonde

\section{To cite this version:}

Maya A Yampolsky, Alexandria L West, Biru Zhou, Amy Muise, Richard N Lalonde. Divided Together: How Marginalization of Intercultural Relationships Is Associated With Identity Integration and Relationship Quality. Social Psychological and Personality Science, 2020, 10.1177/1948550620962653 . hal-03183015

\author{
HAL Id: hal-03183015 \\ https://hal.science/hal-03183015
}

Submitted on 26 Mar 2021

HAL is a multi-disciplinary open access archive for the deposit and dissemination of scientific research documents, whether they are published or not. The documents may come from teaching and research institutions in France or abroad, or from public or private research centers.
L'archive ouverte pluridisciplinaire HAL, est destinée au dépôt et à la diffusion de documents scientifiques de niveau recherche, publiés ou non, émanant des établissements d'enseignement et de recherche français ou étrangers, des laboratoires publics ou privés. 
See discussions, stats, and author profiles for this publication at: https://www.researchgate.net/publication/344179751

\section{Divided Together: How Marginalization of Intercultural Relationships Is Associated With Identity Integration and Relationship Quality}

Article in Social Psychological and Personality Science · September 2020

DOI: $10.1177 / 1948550620962653$

CITATIONS

READS

0

494

5 authors, including:

Maya A. Yampolsky

Laval University

14 PUBLICATIONS 169 CITATIONS

SEE PROFILE

TIR Biru Zhou

McGill University

12 PUBLICATIONS 87 CITATIONS

SEE PROFILE

Some of the authors of this publication are also working on these related projects:

Consequences of Cultural Frame Switching View project

Sacrifice detection \& gratitude View project

Alexandria West

York University

7 PUBLICATIONS 38 CITATIONS

SEE PROFILE

Amy Muise

York University

101 PUBLICATIONS 2,928 CITATIONS

SEE PROFILE 
Divided together: How marginalization of intercultural relationships is associated with identity integration and relationship quality

Maya A. Yampolsky ${ }^{1}$, Alexandria L. West² ${ }^{2}$ Biru Zhou ${ }^{3}$, Amy Muise ${ }^{4}$ and Richard N. Lalonde $^{4}$

1. Université Laval, 2. Duke University, 3. McGill University, 4. York University 
Maya A. Yampolsky is an Assistant Professor at Université Laval. Her research examines how multicultural identification and intercultural relationships are connected to broader context factors such as acculturation, enculturation and racism.

Alexandria West is a Postdoctoral Associate at Duke University. Her research tests how the processes biculturals and intercultural couples use to negotiate their cultures affect them psychologically and socially.

Biru Zhou is a Research Associate at McGill University. Her research is on interpersonal relationships and social support, as well as sociocultural determinants of mental health.

Amy Muise is an Assistant Professor and York Research Chair in Relationships and Sexuality at York University. She studies romantic relationships, sexuality, and motivation.

Richard N. Lalonde is a Professor at York University. His research is at the intersection of culture and intergroup relations, with a focus on issues such as acculturation, bicultural identity and discrimination. 


\section{Acknowledgments}

This research was supported by a Small Institutional Grant via York University from the Social Sciences and Humanities Research Council of Canada (SSHRC), a start-up grant and a postdoctoral fellowship from the Fonds de Recherche Québécois sur la Société et la Culture (FRQSC) awarded to Maya A. Yampolsky, as well as a SSHRC Insight grant and Canadian Foundation for Innovation grant awarded to Amy Muise, and a SSHRC Insight grant held by Richard Lalonde. The research was also supported by a SSHRC doctoral fellowship and an Ontario Graduate Scholarship awarded to Alexandria West. The authors would like to thank the team of research assistants for their dedication, passion and teamwork: Justin Michel, Hamza Sibai, Gil Kim, Rebecca Adams, Victoria Ingram, Hyunjin Richard Seung, Nathan MacAlpine, Dolly Mehta, Mahua Das, Ayesha Sikdar, Kevin Philip Lee, Phyllis Mobbs, Amrita Chopra, Kelly Le, Amina Yousaf and Alyssa Di Bartolomeo. The authors would also like to express their appreciation to the participants for generously giving their time. 


\begin{abstract}
Despite the growing prevalence of intercultural romantic relationships—in which partners identify with different racial, national or religious backgrounds—people in intercultural relationships still face marginalization and disapproval from others. Relationship marginalization sends a message to couples that they do not belong together, and partners may feel that their cultural identity and their relationship are disconnected. Two studies — one study of people in intercultural relationships and one of both members of intercultural couples— showed that when people perceived greater relationship marginalization, they were more likely to separate their couple identity from their cultural identity or believe they had to choose between these identities, and they were less likely to integrate these identities. Less integration and more separation between a person's couple and cultural identities was associated with lower relationship quality for both partners. The findings suggest that marginalization can create challenges for the maintenance and quality of intercultural relationships.
\end{abstract}

Keywords: Intercultural couples, identity integration, marginalization, relationship quality 
Intercultural relationships — relationships in which partners identify with different cultures or ethnicities (Livingston \& Brown, 2017) — are integral to human history by virtue of migration and intergroup contact (Kramsch \& Uryu, 2012). These relationships have been steadily increasing in Canada (4.6\%; Statistics Canada, 2011) and the United States (10.2\%; Rico, Kreider \& Anderson, 2018). Despite the growing prevalence and visibility of intercultural relationships, prejudice and discrimination against intercultural couples continues (Valentine, 2018), with people demonstrating explicit and implicit bias (Skinner \& Rae, 2019), and even disgust (Skinner \& Hudac, 2017), towards intercultural relationships. Marginalization of intercultural couples sends a message to partners in these couples that they do not belong together, and may suggest that their couple identity (e.g., "lover,” “partner,” or “spouse”) and their cultural identity (e.g., Korean-American)

are irreconcilable and cannot be integrated. This fragmented identity experience may play a role in the quality of the romantic relationship. The current research is the first to investigate whether perceived marginalization is associated with how people in intercultural relationships negotiate their couple and cultural identities as well as how a person's identity negotiation is associated with both partners' relationship quality.

\section{Marginalization of Intercultural Relationships}

Relationship marginalization involves actual or perceived social disapproval of a relationship from family, friends, and society (Lehmiller \& Agnew, 2006). Despite their growing presence, intercultural couples are still a minority who are stigmatized for violating the strong cultural norm of endogamy (e.g., Gaines \& Agnew, 2003; Gaines, Clark \& Afful, 2015; Moran, 2004). Norm violation tends to be met with social disapproval (Bell \& Hastings, 2015; Lehmiller \& Agnew, 2006) as well as prejudice and 
discrimination (Killian, 2013; Lewandowski \& Jackson, 2001). The marginalization of intercultural couples has a long history. Racial hierarchies embedded in colonization and slavery constructed Whites as superior and non-Whites as inferior, thereby justifying the subordination, exploitation and enslavement of racialized minorities (Hall, 1995). Current marginalization of intercultural relationships is rooted in these essentialist beliefs that racial separation is the natural order of social organization, including mate selection (Killian, 2013). In the first half of the $20^{\text {th }}$ century in America, intercultural relationships were marginalized through institutional measures such as laws that made such unions illegal and subject to persecution (Fang, Sidanius \& Pratto, 1998). It was not until 1967 that the Loving v. Virginia case won interracial couples the right to marry (Wardle, 1998). Social shifts like the civil rights movement and the legalization of interracial relationships have yielded more favorable explicit attitudes towards these couples (Killian, 2013; Uskul, Lalonde, \& Konanur, 2011). However, intercultural couples may still face disapproval and marginalization from society and close others. Recent experimental studies find that monocultural Americans express explicit and implicit bias against interracial couples (Skinner \& Rae, 2019), and implicitly react with disgust towards interracial couples, which in turn leads to implicit dehumanization (Skinner \& Hudac, 2017).

Marginalization experiences can heavily impact relationship quality and longevity. Support for a relationship from one’s social network has been shown to predict greater relationship well-being (Blair \& Holmberg, 2008) and quality (Sprecher \& Felmlee, 1992). Disapproval of interracial, same-sex or age-gap relationships by society and close others has been associated with lower relationship investment (Lehmiller \& 
Agnew, 2006). In another study of Black and White interracial couples, parental disapproval of the relationship was associated with discomfort, awkwardness, and anxiety for both partners in the relationship (Bell \& Hastings, 2015). We have yet to understand, however, how such relationship marginalization is potentially associated with how partners integrate their cultural and couple identities.

Marginalization can exacerbate inter-identity conflict, and make people feel divided (Benet-Martinez \& Haritatos, 2005; Yampolsky \& Amiot, 2016). To illustrate, consider a fictitious couple, Noah, who identifies as Jewish, and his partner Karuna, who is West Indian. Noah’s parents have expressed that they would not accept the relationship and are distressed that Noah is partnered with an "outsider.” In response, Noah has concealed his relationship with Karuna from his family. Noah identifies as Karuna’s partner when they are together, but he experiences the disapproval of his intercultural relationship as a psychological barrier to reconciling his relationship with Karuna and his Jewish identity. When Noah is with his parents, his Jewish identity is active, but he suppresses his identity as Karuna’s partner. Although Karuna understands Noah’s desire to avoid tensions with his family given their disapproval, Karuna experiences Noah's reticence to open up about his Jewish side, or to introduce her to his family as a choice that distances Karuna from this fundamental part of his existence, his cultural identity, and she feels rejected. Karuna also fears that their future together is uncertain if Noah cannot share all of himself with her in their partnership. In our example couple, Noah has been made to feel that the self-descriptions “I am Jewish” and "I am Karuna’s partner" are mutually exclusive and divided. The current research proposes that this fragmented and conflicted identity experience may not be isolated to one person in the couple and 
may also carry over to one’s partner in the couple. Since one partner does not have access to all of the important aspects of their partner, they may feel that they are being kept at a distance, which could hinder their relationship satisfaction and desire to invest in and maintain the relationship.

\section{Couple and cultural identity integration in intercultural couples}

Our social identities are core facets of who we are. They are how we define ourselves and are inextricably connected to our relationships with others. Cultural identity refers to the sense that one is a member of their cultural group (Amiot, de la Sablonnière, Terry \& Smith, 2007), and feels connected to the values and norms associated with their cultural group(s) (Phinney \& Devich-Navarro, 1997; Schwartz et al., 2007). Couple identity refers to the sense of "we-ness" that develops in a relationship, a shared interpersonal space where both partners construct and experience their connection to each other and define themselves by their belonging to the relationship (Fergus \& Reid, 2001; Reid et al., 2006). It is a cognitive interdependence involving the perception that “myself” and "my partner” overlap (Alea, Singer \& Labunko, 2015), as well as the experience of one's social role as a partner (e.g., husband, wife, spouse; Aron, Aron \& Norman, 2001; Aron, Paris \& Aron, 1995). Interdependence in a relationship is associated with greater marital satisfaction (Aron, Aron \& Smollan, 1992), and greater couple identity clarity has been associated with greater relationship commitment (Emery et al., 2020). As individuals in intercultural couples become closer, however, they are inevitably confronted by the differences in their cultural worldviews, along with the relationship marginalization of their non-normative pairing (Karis \& Killian, 2011). They 
are thus faced with negotiating the potential discrepancies between their cultural identities and their couple identities.

When a social identity is devalued, there is a greater likelihood for individuals to disidentify with the devalued identity (Branscombe et al., 1999). Perceived marginalization of one's relationship may put partners in the position of having to choose between their cultural and couple identities, thereby threatening the relationship satisfaction that is associated with a strong couple identity. Past research has shown that when individuals can connect their multiple identities, they experience greater wellbeing, but when their identities are disconnected, they experience lower well-being (Yampolsky, Amiot \& de la Sablonnière, 2016). In the context of romantic relationships, partners' ability to integrate their couple and cultural identities may be particularly relevant for relationship quality.

According to the Cognitive-Developmental Model of Social Identity Integration (CDSMII; Amiot et al., 2007), there are several ways that people can integrate or reconcile multiple social identities ${ }^{1}$ : integration, compartmentalization and categorization. Integration is qualified by having multiple, connected identities that form a cohesive whole; one perceives a common ground between identities, and the differences between identities are seen as advantageous and complementary. Additionally, a superordinate identity can bridge the different identities under a shared umbrella. In the context of intercultural couples, Killian’s (2013) exploratory qualitative work showed

\footnotetext{
${ }^{1}$ In our current research, we employ three of the four configurations since the anticipatory categorization configuration examines the anticipation of developing a new social identity, while the current study focuses on people who already have these identities.
} 
that many couples tend to identify with being human or with a common social identity, such as religion, which can serve as a bridge between their ethnic backgrounds and the formation of their couple. Furthermore, Seshadri and Knudson-Martin (2013) showed that many couples focused on common points between each partner's cultural backgrounds as a means to unite their cultural and couple identities across social divisions. Identity integration tends to be associated with positive outcomes across cultural and general social identity domains, including well-being (Yampolsky et al., 2016), increased tolerance towards dissimilar others (Huff, Lee \& Hong, 2017), and the creation of a common ingroup identity over time (Amiot, Terry \& McKimmie, 2012).

Compartmentalization is characterized by having multiple identities that are kept separate within the self-concept. One identifies with each identity in its respective context (e.g., couple identity), while suppressing the other identity (e.g., cultural identity). In compartmentalization, one identity is not just more salient than the other while in its context, but the other identity is being actively suppressed. The differences between identities are seen as clashing and irreconcilable. Prior work on intercultural couples (Killian, 2013) found that some couples perceive contradiction between their intercultural couple and their own cultural/racialized background. Compartmentalizing cultural identities is associated with lower well-being (Yampolsky et al., 2016).

Another approach to managing multiple identities is to prioritize one identity. This categorization approach, has one predominant identity with others becoming less central to the self-concept. In the current research, we distinguish between categorization to one’s cultural group (culture categorization), where one identifies predominantly with one's culture and excludes the couple identity from the self-concept, and categorization to 
one's relationship (couple categorization), where one identifies predominantly with one's couple, and excludes their cultural identity from the self-concept. Previous work on intercultural couples found that some interracial couples formed their couple identities by explicitly removing the focus on cultural differences in the couple (Killian, 2013). Findings about the consequences of categorization are ambiguous (e.g., Yampolsky et al., 2013), and so examining categorization within the context of the marginalization experience of intercultural couples was exploratory in nature.

The current research is the first to directly investigate identification processes in intercultural couples in the context of marginalization, which acts as an internalized barrier to partners integrating their cultural and couple identities. Previous work has shown that the experience of racism directly predicts greater compartmentalization of one's cultural identities, and indirectly predicts lower integration of these identities (Yampolsky \& Amiot, 2016). We therefore expected that marginalization of the intercultural couple would predict greater compartmentalization of one’s couple and cultural identities and predict lower integration of these identities.

\section{Identity configurations and relationship quality}

To establish the importance of identification in the context of intercultural couples, the current studies also focused on how the identity configurations (integration, compartmentalization, categorization) were associated with relationship quality, specifically relationship investment (the devotion of one's own personal and psychological resources to the relationship), commitment (the psychological attachment to the relationship and the intention to remain with the partner) and satisfaction (the experience of positive affect and attraction with the relationship) (Rusbult, 1980; 
Sternberg, 1986). We know that at the individual-level, more integration is associated with greater personal well-being, and compartmentalization is associated with lower wellbeing (Yampolsky, Amiot \& de la Sablonnière, 2016). We expected that the configuration of one's cultural and couple identities would also be associated with their relationship quality. Keeping one’s identities separate and context bound may have the effect of minimizing one's degree of couple investment by excluding the relationship from other key parts of their lives. Since people in close relationships often influence each other's attitudes, cognitions, and behaviors (Kenny, Kashy \& Cook, 2006; Rusbult \& Van Lange, 2008), a divided identity experience within the self can potentially extend to one's partner, where the partner feels divided from the whole self of their significant other. On the other hand, by integrating a relationship with one’s cultural identity, partners are effectively connecting these important pieces of their lives. The work involved in integrating one's identities in the context of the couple is an investment of one’s own psychological resources to one’s self-definition as a partner.

\section{The Current Studies}

Across two studies, we examined how perceived marginalization of one’s intercultural relationship predicts both the person's own cultural and couple identity configuration (Studies 1 and 2), as well as their partner's cultural and couple identity configuration (Study 2). We also investigated how a person’s identity configurations predict their own relationship investment, commitment and satisfaction (Studies 1 and 2) as well as their partner's relationship quality (Study 2). We predicted that greater marginalization would be associated with lower integration, and greater compartmentalization. We expected integration to be associated with greater relationship 
investment, commitment and satisfaction, and compartmentalization to be associated with lower relationship investment, commitment and satisfaction. In Study 1, we recruited people in intercultural relationships to test these associations at the individual level. In Study 2, we extended the findings by recruiting intercultural couples ${ }^{2}$ to test how one's perception of marginalization was associated with a person's own identity configuration and relationship quality (actor effect) as well as their partner's identity configuration and relationship quality (partner effect; see Figures 1 and 2). We also tested the generalizability of the findings across relationship duration and bicultural status (for more information see the online supplementary materials).

Figure 1: Conceptual model of both actor and partner effects of perceived marginalization to couple and cultural identity configurations.

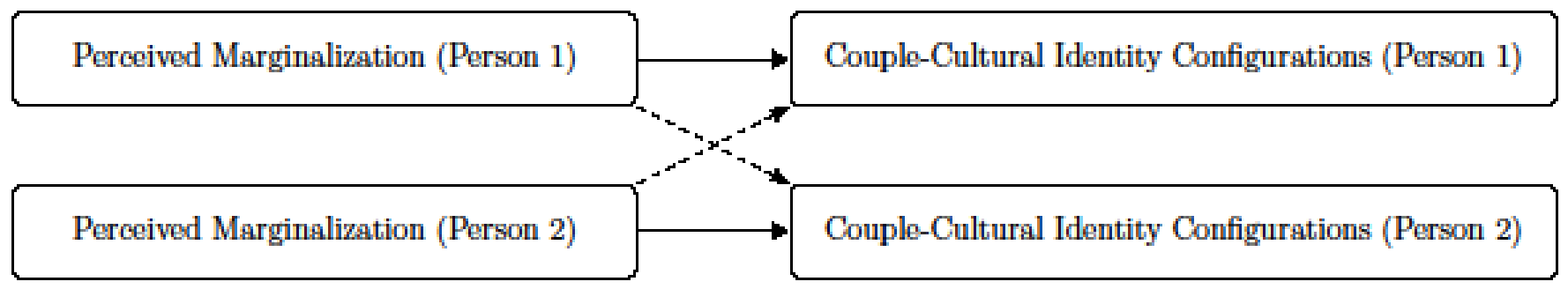

Figure 2: Conceptual model of both actor and partner effects of couple and cultural identity configurations to relationship quality.

${ }^{2}$ It should be noted that both studies were part of larger surveys examining multiple variables; in the present research we are reporting the measures that are relevant to the current questions. 


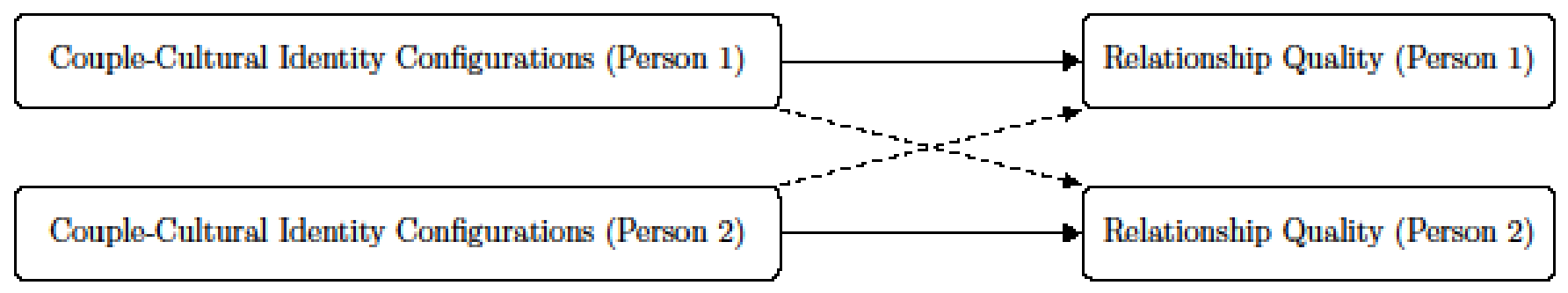

\section{Study 1}

\section{Participants}

The sample consisted of 242 participants (104 women, 131 men, 7 other, $M_{\text {age }}=$ 37.16, $\left.S D_{\text {age }}=9.99\right)$. Participants were recruited via Prolific, a crowdsourcing platform for research. According to participants’ self-reported ethnicity, the sample consisted of individuals who were White (70.4\%), Black (3.8\%), Latinx (9.6\%), Native (0.01\%), Middle Eastern (0.01\%), South Asian (2.9\%), East Asian (5.8\%), Southeast Asian (0.01\%), and Mixed (4.2\%). Couples’ reported relationship statuses included casual dating (0.5\%), long-term dating (2.5\%), engaged (3.2\%), common law (5.5\%), and married (91.5\%). The average duration of the relationship was 10 years $(M=10.00$ years, $S D=7.97$ years $)$.

Measures $^{3}$

Descriptive statistics for the following measures can be found in Table 1.

Perceived relationship marginalization. The extent to which participants perceived social disapproval and exclusion towards their intercultural relationship from their family, friends, and society was measured using the Relationship Marginalization

\footnotetext{
3 The measures for both studies are included in the online supplement document accompanying this article.
} 
Scale (Lehmiller \& Agnew, 2006), consisting of 6 items ( $\alpha=$.76; e.g, "My friends approve of my relationship” (reverse coded)) rated on a 9-point Likert scale ranging from 1 (Not true of my relationship at all) to 9 (very true of my relationship).

Couple and cultural identity configurations. The configuration of one's couple and cultural identities was assessed using four vignettes, one for each configuration: Categorization to the relationship (R), Categorization to their own culture (C), Compartmentalization of the couple and cultural identities, and Integration of couple and cultural identities. These configuration vignettes were based on the CDSMII model (Amiot, de la Sablonnière, Terry \& Smith, 2007). Each vignette provided a brief and illustrative representation of its configuration. Participants indicated the extent to which each of the four configurations represented their experience (1: not at all to 7: exactly).

Relationship investment, commitment and satisfaction. The Investment Model Scale (Rusbult, Martz \& Agnew, 1998) assessed relationship investment (5 items, $\alpha=$ .78; e.g. "I have put a great deal into our relationship that I would lose if the relationship were to end.”) and commitment (3 of the 7 original items were selected for brevity, $\alpha=$ .94; e.g. "I want our relationship to last for a very long time.”) from 0 (do not agree at all) to 8 (agree completely). Satisfaction was assessed with the three-item subscale $(\alpha=$ .97; e.g. “How satisfied are you with your relationship?”) from the Perceived Relationship Quality Components Inventory (Fletcher, Simpson \& Thomas, 2000) on a scale from 1 (not at all) to 7 (extremely).

\section{Results and discussion}

Participants reported relatively low levels of relationship marginalization in this sample, and integration was the most highly endorsed of the identity configurations (see 
Table 1). In line with our predictions, people who perceived greater relationship marginalization from others reported lower integration of their couple and cultural identities. In contrast, people who perceived greater marginalization reported greater compartmentalization as well as greater couple and culture categorization (see Table 1). Regression analyses were run with all four configurations simultaneously entered to investigate how each identity configuration predicted investment, commitment and satisfaction, respectively, once controlling for the shared variance between the configurations (see Table 2). As predicted, these analyses showed that integration was significantly associated with greater investment, commitment and satisfaction, whereas culture categorization (i.e., identified predominantly with their culture) was associated with lower commitment and satisfaction.

The results from Study 1 suggest that individuals who feel more marginalized are more likely to feel divided and disconnected at the identity level, whether through separating their identities or feeling forced to choose between them. The ability to integrate one's couple and cultural identities is associated with greater relationship quality, while categorization - and to a certain extent compartmentalization - are associated with lower relationship quality. 
Table 1

Study 1: Descriptives and correlations for couple and cultural identity configurations, relationship marginalization, investment, commitment and satisfaction.

\begin{tabular}{lcccccccccc}
\hline \multicolumn{1}{c}{} & $\mathrm{M}$ & $\mathrm{SD}$ & 1 & 2 & 3 & 4 & 5 & 6 & 7 \\
\hline 1. Integration & 5.11 & 1.43 & - & & & & & & \\
2. Compartmentalization & 2.16 & 1.42 & $-.49^{* *}$ & - & & & & & \\
3. Couple Categorization & 2.95 & 1.81 & $-.16^{*}$ & $.31^{* *}$ & - & & & & \\
4. Culture Categorization & 2.26 & 1.34 & $-.27^{* *}$ & $.45^{* *}$ & $.15^{*}$ & - & & & \\
5. Relationship Marginalization & 2.22 & 1.17 & $-.23^{* *}$ & $.26^{* *}$ & $.21^{* *}$ & $.20^{* *}$ & - & & \\
6. Investment & 6.76 & 1.57 & $.20^{* *}$ & -.08 & .01 & $-.15^{*}$ & -.12 & - & \\
7. Commitment & 8.21 & 1.43 & $.32^{* *}$ & $-.23^{* *}$ & .01 & $-.24^{* *}$ & $-.38^{* *}$ & $.47^{* *}$ & - \\
8. Satisfaction & 5.78 & 1.28 & $.35^{* *}$ & $-.22^{* *}$ & .05 & $-.27^{* *}$ & $-.38^{* *}$ & $.41^{* *}$ & $.75^{* *}$ \\
\hline
\end{tabular}

Note: $N=240,{ }^{*} p<.05,{ }^{* *} p<0.01$ level. 


\section{Table 2}

Study 1: Regression findings for couple and cultural identity configurations to relationship investment, commitment and satisfaction.

\begin{tabular}{|c|c|c|c|c|c|c|c|c|c|}
\hline & \multicolumn{3}{|c|}{ Investment } & \multicolumn{3}{|c|}{ Commitment } & \multicolumn{3}{|c|}{ Satisfaction } \\
\hline & $\mathrm{B}$ & Std Error & [95\% CI] & $\mathrm{B}$ & Std Error & [95\% CI] & B & Std Error & {$[95 \% \mathrm{CI}]$} \\
\hline Integration & $.22 * *$ & .08 & {$[.060, .377]$} & $.27 * * *$ & .07 & {$[.125, .420]$} & $.28 * * *$ & .06 & {$[.161, .409]$} \\
\hline Compartmentalization & .07 & .09 & {$[-.105, .255]$} & -.06 & .08 & {$[-.242, .092]$} & -.02 & .07 & {$[-.151, .129]$} \\
\hline Couple categorization & .04 & .06 & {$[-.080, .152]$} & .07 & .05 & {$[-.029, .186]$} & $.10^{*}$ & .04 & {$[.014$, .194] } \\
\hline Culture categorization & $-.15^{\dagger}$ & .08 & {$[-.321, .009]$} & $-.17^{*}$ & .07 & {$[-.328,-.022]$} & $-.19 * *$ & .06 & {$[-.327,-.070]$} \\
\hline Adjusted $\mathrm{R}^{2}$ & \multicolumn{3}{|c|}{$.04 *$} & \multicolumn{3}{|c|}{$.13^{* * *}$} & \multicolumn{3}{|c|}{$.16^{* * *}$} \\
\hline
\end{tabular}

Notes: $N=240 .{ }^{*} p<.05,{ }^{*} p<.01,{ }^{* * *} p<.001 . C I=$ confidence interval. 


\section{Study 2}

In Study 2, we extend Study 1 by recruiting both members of intercultural couples to investigate the links between marginalization, the couple and cultural identity configurations and both partners' relationship quality, given the mutual, interdependent influence of partners. We predicted that a person's perception of marginalization would predict lower integration and greater compartmentalization for themselves (actor effect) and would also predict lower integration and greater compartmentalization for their partner (partner effect). Moreover, we predicted that a person's integration would predict greater relationship quality for both themselves and their partner, whereas compartmentalization would predict lower relationship quality.

\section{Method}

\section{Participants}

Two different samples from separate online studies on intercultural couples were combined to increase statistical power ${ }^{4}$. Two hundred and fifty-eight couples $(N=516$; 248 men, 261 women, 7 unspecified; $\left.M_{\text {age }}=31.65, S D_{\text {age }}=9.12\right)$ currently in a romantic relationship participated in this study. The cultural composition of participants was diverse. Their self-reported ethnicity was as follows: White (56\%), Black (6\%), Latinx (7\%), Native (0.01\%), Middle Eastern (3\%), South Asian (8\%), East Asian (8\%), Southeast Asian (4\%), and Mixed (7\%). Couples’ reported relationship statuses included

\footnotetext{
${ }^{4}$ One sample ( $\left.\mathrm{n}=204\right)$ recruited couples from the broader community via convenience sampling, snowballing and community outreach. Flyers advertising the study were placed at local parks, community centers, university campuses, and at other popular spots in the city of Toronto. The other sample recruited couples using Prolific $(n=312)$. The inclusion criteria and the key measures were the same, except that the community sample only included heterosexual couples while the Prolific sample was open to couples of all sexual orientations. If one partner in a couple filled out the questionnaire, but the other did not, their data was excluded from the analyses.
} 
casual dating (2\%), committed relationship (66.7\%), engaged (4.9\%), cohabiting (8.8\%), and married/common law (16.7\%).

\section{Measures}

The same measures from Study 1 for couple and cultural identity configurations, perceived relationship marginalization, and relationship investment and commitment were used for Study 2. For relationship satisfaction, the community sample used the satisfaction subscale from the Investment Model Scale (Rusbult et al., 1998), while the Prolific sample used the satisfaction items from the Perceived Relationship Quality Components (Fletcher et al., 2000). Though two different scales were used to assess satisfaction, the items overlapped in content (e.g., Investment Model Scale: “I am happy with my relationship” and PRQC: “How happy are you with your relationship”). In order to analyze satisfaction in a way that was equivalent across samples, the items from these two satisfaction measures were standardized and the z-scores were combined for analysis (see Webster, Laurenceau, Smith, Mahaffey, Bryan, \& Brunell, 2015 for an example of standardization of measures between samples).

\section{Results and discussion}

In order to account for the interdependent nature of the data collected from both partners in the intercultural couples in this study, we used Actor-Partner Interdependence Models (APIM) to test our hypotheses. Descriptive statistics for the measures are presented in Table 3. As in Study 1, perceived relationship marginalization was relatively low. Integration was the most highly endorsed identity configuration. Correlations between actor and partner variables are presented in Table 4. 


\section{Table 3}

Study 2: Descriptives for couple and cultural identity

configurations, relationship marginalization, investment, commitment and satisfaction.

\begin{tabular}{lcc}
\hline & $\mathrm{M}$ & $\mathrm{SD}$ \\
\hline Integration & 5.31 & 1.55 \\
Compartmentalization & 1.79 & 1.24 \\
Couple categorization & 2.89 & 1.76 \\
Culture categorization & 2.17 & 1.36 \\
Marginalization & 2.05 & 1.20 \\
Investment & 6.87 & 1.48 \\
Commitment & 8.55 & 1.01 \\
Satisfaction & .00 & 1.00 \\
$\quad$ Prolific subsample $(\mathrm{n}=308)$ & 6.10 & 1.10 \\
\multicolumn{1}{c}{ Community subsample $(\mathrm{n}=204)$} & 7.87 & 1.21 \\
\hline
\end{tabular}

Note: $N=510$. The satisfaction score was created by standardizing the two measures and the z-scores were combined for analysis. The descriptives for the subsamples are provided. The Prolific subsample was administered the Perceived Relationship Quality Components Inventory (1 to 7 scale), and the community subsample was administered the Investment Model Scale (0 to 8 scale) 


\section{Table 4}

Study 2: Within-person correlations between couple and cultural identity configurations, relationship marginalization, investment, commitment and satisfaction.

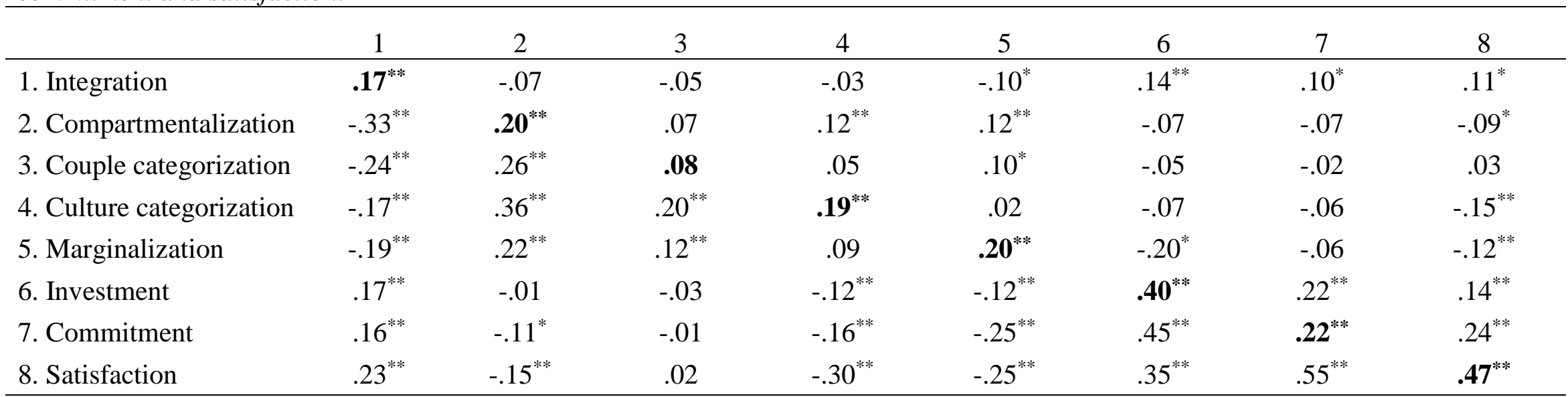

Note: $N=510$. Correlation coefficients along the diagonal (in bold) are between actors and partners on the same variable, which indicate the degree of similarity between their reports. Correlation coefficients above the diagonal are between the actor and partner variables, which indicate how the actor and partner reports are related. Correlations below the diagonal are between each of the actor variables. ${ }^{*} p<.05 ;{ }^{* *} p<.01$. 


\section{Perceived marginalization to couple and cultural identity configurations}

Four APIM analyses were conducted to test the associations between one's own and one's partner's marginalization experiences with each of the four couple-cultural identity configurations (see Table 5). First, consistent with our hypotheses and the results from Study 1, people who perceived more marginalization reported lower identity integration. We also found that people who perceived more marginalization reported more categorization towards their couple identity, and towards their cultural identity. In addition, when people perceived greater relationship marginalization, their partner also reported marginally higher identity compartmentalization and couple categorization, suggesting that the more a person perceived marginalization toward their relationship, the more their partner kept their identities separate or identified solely with the couple. 
Table 5

Study 2: APIM results for relationship marginalization to actor and partner relationship couple-cultural identity configurations.

\begin{tabular}{|c|c|c|c|c|c|c|c|c|}
\hline & \multicolumn{2}{|c|}{ Integration } & \multicolumn{2}{|c|}{ Compartmentalization } & \multicolumn{2}{|c|}{ Couple Categorization } & \multicolumn{2}{|c|}{ Culture Categorization } \\
\hline & $\begin{array}{c}b(S E) \\
{[95 \% \mathrm{CI}]}\end{array}$ & $p$ & $\begin{array}{c}b(S E) \\
{[95 \% \mathrm{CI}]}\end{array}$ & $p$ & $\begin{array}{c}b(S E) \\
{[95 \% \mathrm{CI}]}\end{array}$ & $p$ & $\begin{array}{c}b(S E) \\
{[95 \% \mathrm{CI}]}\end{array}$ & $p$ \\
\hline \multicolumn{9}{|l|}{ Marginalization } \\
\hline Actor & $\begin{array}{c}-.21 *(.06) \\
{[-.33,-.10]}\end{array}$ & $<.001$ & $\begin{array}{l}.21 *(.05) \\
{[.12, .30]}\end{array}$ & $<.001$ & $\begin{array}{l}.17 *(.07) \\
{[.04, .30]}\end{array}$ & .01 & $\begin{array}{c}.10(.05) \\
{[-.004, .20]}\end{array}$ & .06 \\
\hline Partner & $\begin{array}{r}-.08(.06) \\
{[-.20, .03]}\end{array}$ & .13 & $\begin{array}{c}.08(.05) \\
{[-.01, .17]}\end{array}$ & .07 & $\begin{array}{c}.11(.07) \\
{[-.02, .24]}\end{array}$ & .10 & $\begin{array}{c}-.007(.05) \\
{[-.11, .09]}\end{array}$ & .90 \\
\hline
\end{tabular}

Note. *These coefficients remained statistically significant after applying the multiple testing correction using the Benjamin-Hochberg procedure (McDonald, 2014). 


\section{Couple and cultural identity configurations with relationship investment, commitment and satisfaction}

As depicted in Table 6, a person’s identity configuration was associated with both their own and their partner’s relationship quality. Specifically, when people integrated their identities, they reported more investment, commitment, and satisfaction, and their partners reported more investment (and marginally more commitment). In contrast, when people compartmentalized their identities, they reported less commitment and satisfaction, and their partner reported marginally less investment. When people categorized towards their cultural identity, they reported lower investment, commitment, and satisfaction, and their partner also reported lower satisfaction. 
Table 6

Study 2: APIM results for couple and cultural identity configurations to actor and partner relationship investment, commitment and satisfaction.

\begin{tabular}{|c|c|c|c|c|c|c|c|}
\hline & & \multicolumn{2}{|c|}{ Investment } & \multicolumn{2}{|c|}{ Commitment } & \multicolumn{2}{|c|}{ Satisfaction } \\
\hline & & $\begin{array}{c}b(S E) \\
{[95 \% \mathrm{CI}]}\end{array}$ & $p$ & $\begin{array}{c}b(S E) \\
{[95 \% \mathrm{CI}]}\end{array}$ & $p$ & $\begin{array}{c}b(S E) \\
{[95 \% \mathrm{CI}]}\end{array}$ & $p$ \\
\hline \multicolumn{8}{|l|}{ Integration } \\
\hline & Actor & $\begin{array}{l}.14(.04)^{*} \\
{[.06, .22]}\end{array}$ & .001 & $\begin{array}{l}.10(.03)^{*} \\
{[.04, .15]}\end{array}$ & .001 & $\begin{array}{l}.14(.03)^{*} \\
{[.09, .20]}\end{array}$ & $<.001$ \\
\hline & Partner & $\begin{array}{l}.11(.04)^{*} \\
{[.03, .19]}\end{array}$ & .009 & $\begin{array}{c}.05(.03) \\
{[-.008, .10]}\end{array}$ & .09 & $\begin{array}{c}.04(.03) \\
{[-.01, .09]}\end{array}$ & .12 \\
\hline \multicolumn{8}{|l|}{ Compartmentalization } \\
\hline & Actor & $\begin{array}{c}.01(.05) \\
{[-.09, .12]}\end{array}$ & .78 & $\begin{array}{c}-.08(.04) \\
{[-.15,-.01]}\end{array}$ & .03 & $\begin{array}{l}-.12(.03)^{*} \\
{[-.18,-.05]}\end{array}$ & .001 \\
\hline & Partner & $\begin{array}{l}-.09(.05) \\
{[-.19, .01]}\end{array}$ & .08 & $\begin{array}{c}-.04(.04) \\
{[-.11, .03]}\end{array}$ & .25 & $\begin{array}{l}-.05(.03) \\
{[-.12, .02]}\end{array}$ & .16 \\
\hline \multicolumn{8}{|l|}{ Couple Categorization } \\
\hline & Actor & $\begin{array}{l}-.02(.04) \\
{[-.09, .05]}\end{array}$ & .57 & $\begin{array}{l}-.004(.03) \\
{[-.05, .05]}\end{array}$ & .87 & $\begin{array}{c}.01(.02) \\
{[-.04, .06]}\end{array}$ & .62 \\
\hline & Partner & $\begin{array}{l}-.04(.04) \\
{[-.11, .03]}\end{array}$ & .26 & $\begin{array}{c}-.008(.03) \\
{[-.06, .04]}\end{array}$ & .77 & $\begin{array}{c}.02(.02) \\
{[-.03, .06]}\end{array}$ & .53 \\
\hline
\end{tabular}


Marginalization of intercultural couples, identity integration, relationship quality 27

\begin{tabular}{|c|c|c|c|c|c|c|c|}
\hline \multicolumn{8}{|l|}{ Culture Categorization } \\
\hline & \multirow[t]{2}{*}{ Actor } & $-.11(.05)^{*}$ & .02 & $-.11(.03)^{*}$ & .001 & $-.21(.03)^{*}$ & \multirow[t]{2}{*}{$<.001$} \\
\hline & & {$[-.21,-.02]$} & & {$[-.18,-.05]$} & & {$[-.27,-.15]$} & \\
\hline & Partner & {$[-.15, .04]$} & & {$[-.08, .04]$} & & {$[-13,-.01]$} & .02 \\
\hline
\end{tabular}

Note. *These coefficients remained statistically significant after applying the multiple testing correction using the Benjamin-Hochberg procedure (McDonald, 2014). The satisfaction score was created by standardizing the two measures and the z-scores were combined for analysis. 


\section{General Discussion}

Social marginalization of intercultural relationships can create an unwelcoming environment for intercultural couples, which they may internalize in the form of feeling divided between their cultural identity and their couple identity. The present research investigated how perceived relationship marginalization is associated with couple and cultural identity configurations. Across both studies, perceived relationship marginalization was relatively low, and individuals who reported lower perceived marginalization also reported greater integration between their couple and cultural identities; this suggests that in the absence of marginalization, many intercultural couples are able to connect these core parts of themselves. In contrast, those reporting greater perceived relationship marginalization were more likely to compartmentalize their cultural and couple identities; one’s own perceived marginalization was also associatedthough marginally — with their partner reporting greater compartmentalization. Overall, participants' bicultural status and relationship length did not moderate these results (see online supplementary materials). These findings suggest that when people experience a social context of disapproval, their ability to connect their cultural identities with their couple identity may be inhibited, and instead they keep these key parts of themselves separate. This is consistent with past work showing that experiencing racism is associated with compartmentalizing one’s multiple cultural identities (Yampolsky \& Amiot, 2016).

In addition, the current findings showed that perceived marginalization was associated with both identifying predominantly with one’s relationship and identifying predominantly with one’s culture; in Study 2 we also found that perceived marginalization was associated, albeit weakly, with a partner solely identifying with the 
couple. It is possible that social disapproval creates pressure to choose between key parts of oneself as a show of loyalty (e.g., Rockquemore \& Brunsma, 2002) to either their cultural group or their relationship partner. There may also be a rejection-identification process at work (Branscombe, Schmitt, \& Harvey, 1999) in which marginalization towards one’s relationship is experienced as rejection from one’s cultural group, and fuels a protective identification with one's relationship. It is also possible, however, that identifying predominantly with the relationship gives rise to greater perception of marginalization, which would be more consistent with an identification-attribution model (Gonzalez-Backen et al., 2018). The direction of these links can be tested in future studies.

Most research on identifying with more than one culture has prioritized the examination of high vs. low integration, given that integration is an adaptive identity strategy (e.g., Nguyen \& Benet-Martinez, 2013). Here we show that the marginalization experience is not simply associated with lower identity integration, but that it is also associated with people feeling like they need to choose between their identities or to keep them separate. The latter are less adaptive identity experiences. Each of these different identity configurations is its own process with a distinct set of characteristics, mechanisms, and social influences (West, Zhang, Yampolsky \& Sasaki, 2017). It is therefore essential to understand how negative social forces contribute to less adaptive identity strategies. In addition to examining the range of identity configuration processes individually, by recruiting both partners in intercultural relationships in Study 2, we revealed that identity configurations are relevant at the relational level as well. That is, 
perceived marginalization is associated with both partner's identities and a person's identity configuration is associated with both partner's relationship quality.

Identity integration was the most commonly reported identity strategy across both studies, which may be due to our sample reporting lower levels of marginalization. Overall, the findings suggest that integrating one's couple and cultural identities is associated with greater relationship quality for both partners, whereas compartmentalization and categorization to one's culture were associated with lower relationship quality for both partners. It is possible that if an individual is keeping their cultural identity separate from their relationship identity, their partner may feel rejected or excluded from a core aspect of their partner’s life. Future research examining this possibility could inform how one partner's identity configuration is associated with the partner's relationship quality. Interestingly, identifying predominantly with one’s couple over one's culture was associated with greater relationship quality in Study 1, but was unrelated to relationship quality in Study 2. While identifying predominantly with one’s couple may prioritize the couple and therefore enable one to experience greater relationship quality, it may prove difficult and ambivalent since disidentifying with one's own cultural group, and the possibility of cutting ties with close others from one's cultural group, may come at a significant cost to individual well-being (e.g., Smith \& Silva, 2011). Future work can test the potential mediating role of perceived social pressure and divided loyalties.

\section{Limitations and future directions}

The current studies are correlational and cannot confirm the causal direction or appropriately test whether identity configurations are a mechanism linking 
marginalization to relationship quality (Pek \& Hoyle, 2016). However, these findings indicate that identity integration is meaningful for the success and happiness of intercultural couples and may be one process through which marginalization is associated with relationship quality. Future longitudinal and experimental studies can investigate the identity configurations as a potential mediator between relationship marginalization and relationship quality.

This research focused on intercultural couples, but the identity configurations may also be of consequence to couples who identify with different marginalized social categories aside from culture or racialized groups, such as class or sexual orientation. These findings may also apply to couples in which partners are navigating important social identities with their relationship identity, such as politically conservative and liberal identities. Future research could examine whether social identity configuration patterns emerge consistently in couples from different social groups more broadly.

There are also limitations to the current studies that should be addressed in future work. The samples primarily represented cis-gendered and heterosexual individuals, and so future samples will endeavor to be more representative of gender and sexual minorities as we examine these identity experiences. In order to continue building a more global psychology of intercultural couples, future research will need to focus on the identity experiences of intercultural couples in non-Western contexts, which may have different norms and histories around intercultural romance. The measure of marginalization, while reliable and robust, is not elaborate in terms of the range of marginalization experiences that the couples experience. Future work needs to dig deeper into all the facets of 
relationship marginalization of intercultural couples, ranging from disapproval to explicit and implicit racism.

\section{Conclusion}

In sum, the current set of studies examines the context of marginalization facing intercultural couples as a factor that is associated with partners' ability to connect their relationship identity with their cultural identity. Across two studies, perceived relationship marginalization was associated with less adaptive identity configuration strategies, and when people reported less integration and more compartmentalization between their couple and cultural identities, both partners in the relationship reported lower relationship quality. Social identities are the parts of a person that represent their connection to their loved ones and groups. For intercultural couples, how partners integrate the cultural and romantic aspects of the self provides insight into the satisfaction and maintenance of intercultural relationships, and the current research suggests that perceived marginalization creates challenges for people in intercultural relationships to integrate their identities and maintain their relationships over time. 


\section{References}

Alea, N., Singer, J. A., \& Labunko, B. (2015). “We-ness” in relationship-defining memories and marital satisfaction. In K. Skerrett \& K. Fergus (Eds.), Couple Resilience (p. 163-177). Springer. https://doi.org/10.1007/978-94-017-9909-6_9

Amiot, C. E., de la Sablonniere, R., Terry, D. J., \& Smith, J. R. (2007). Integration of social identities in the self: Toward a cognitive-developmental model. Personality and Social Psychology Review, 11(4), 364-388. https://doi.org/10.1177/1088868307304091

Amiot, C. E., Terry, D. J., \& McKimmie, B. M. (2012). Social identity change during an intergroup merger: The role of status, similarity, and identity threat. Basic and Applied Social Psychology, 34(5), 443-455. https://doi.org/10.1080/01973533.2012.712016

Aron, A., Paris, M., \& Aron, E. N. (1995). Falling in love: Prospective studies of self-concept change. Journal of Personality and Social Psychology, 69(6), 1102-1112.

Aron, A., Aron, E. N., \& Norman, C. (2001). The self-expansion model of motivation and cognition in close relationships and beyond. In M. Clark \& G. Fletcher (Eds.), Blackwell Handbook of Social Psychology, Interpersonal Processes (vol. 2, p. 478-501). Oxford: Blackwell.

Aron, A., Aron, E. N., \& Smollan, D. (1992). Inclusion of Other in the Self Scale and the structure of interpersonal closeness. Journal of Personality and Social Psychology, 63(4), 596-612. https://doi.org/10.1037/0022-3514.63.4.596

Bell, G. C., \& Hastings, S. O. (2015). Exploring parental approval and disapproval for Black and White interracial couples. Journal of Social Issues, 71(4), 755-771. https://doi.org/10.1111/josi.12147 
Benet-Martinez, V., \& Haritatos, J. (2005). Bicultural Identity Integration (BII): Components and Psychosocial Antecedents. Journal of Personality, 73(4), 1015-1049. https://doi.org/10.1111/j.1467-6494.2005.00337.x

Blair, K. L., \& Holmberg, D. (2008). Perceived social network support and well-being in samesex versus mixed-sex romantic relationships. Journal of Social and Personal Relationships, 25(5), 769-791. https://doi.org/10.1177/0265407508096695

Branscombe, N. R., Ellemers, N., Spears, R., \& Doosje, B. (1999). The context and content of social identity threat. In N. Ellemers, R. Spears, \& B. Doosje (Eds.), Social identity: Context, commitment, content (p. 35-58). Blackwell Science.

Fang, C. Y., Sidanius, J., \& Pratto, F. (1998). Romance across the social status continuum: Interracial marriage and the ideological asymmetry effect. Journal of Cross-Cultural Psychology, 29(2), 290-305. https://doi.org/10.1177/0022022198292002

Fergus, K. D., \& Reid, D. W. (2001). The couple's mutual identity and reflexivity: A systemicconstructivist approach to the integration of persons and systems. Journal of Psychotherapy Integration, 11(3), 385-410. https://doi.org/10.1023/A:1016658301629

Fletcher, G. J. O., Simpson, J. A., \& Thomas, G. (2000). The measurement of perceived relationship quality components: A confirmatory factor analytic approach. Personality and Social Psychology Bulletin, 26(3), 340-354. https://doi.org/10.1177/0146167200265007

Gaines, S. O., Jr., \& Agnew, C. R. (2003). Relationship maintenance in intercultural couples: An interdependence analysis. In D. J. Canary \& M. Dainton (Eds.), Maintaining relationships through communication: Relational, contextual, and cultural variations (p. 231-253). Lawrence Erlbaum Associates Publishers. 
Gaines, S. O., Jr., Clark, E. M., \& Afful, S. E. (2015). Interethnic marriage in the United States: An introduction. Journal of Social Issues, 71(4), 647-658. https://doi.org/10.1111/josi.12141

Hall, S. (1992). The West and the rest: discourse and power. In S. Hall \& B. Gieben (Eds.) Formations of Modernity (pp. 275-332). The Open University.

Huff, S. T., Lee, F., \& Hong, Y. Y. (2017). Bicultural and generalized identity integration predicts interpersonal tolerance. Journal of Cross-Cultural Psychology, 48(5), 644-666. https://doi.org/10.1177/0022022117701193

Karis, T. A., \& Killian, K. D. (Eds.). (2011). Intercultural couples: Exploring diversity in intimate relationships. Routledge.

Kenny, D. A., Kashy, D. A., \& Cook, W. L. (2006). Methodology in the social sciences (David A. Kenny, Series Editor). Dyadic data analysis. Guilford Press.

Killian, K. (2013). Interracial Couples, Intimacy, and Therapy: Crossing Racial Borders. Columbia University Press.

Kramsch, C., \& Uryu, M. (2012). Intercultural contact, hybridity, and third space. The Routledge handbook of language and intercultural communication, 211-225.

Lehmiller, J. J., \& Agnew, C. R. (2006). Marginalized relationships: The impact of social disapproval on romantic relationship commitment. Personality and Social Psychology Bulletin, 32(1), 40-51. https://doi.org/10.1177/0146167205278710

Lewandowski, D. A., \& Jackson, L. A. (2001). Perceptions of interracial couples: Prejudice at the dyadic level. Journal of Black Psychology, 27(3), 288-303. https://doi.org/10.1177/0095798401027003003 
Livingston, G., \& Brown, A. (2017). Intermarriage in the US 50 years after Loving v. Virginia. Pew Research Center Report. https://www.pewsocialtrends.org/wpcontent/uploads/sites/3/2017/05/Intermarriage-May-2017-Full-Report.pdf

McDonald, J. H. (2014). Multiple comparisons. In J. H. McDonald (Ed.), Handbook of Biological Statistics (3rd ed., p. 254-26). Sparky House Publishing.

Moran, R. F. (2004). Love with a proper stranger: What anti-miscegenation laws can tell us about the meaning of race, sex, and marriage. Hofstra Law Review, 32(4), 1663-1679.

Nguyen, A.-M. D., \& Benet-Martínez, V. (2013). Biculturalism and adjustment: A metaanalysis. Journal of Cross-Cultural Psychology, 44(1), 122-159. https://doi.org/10.1177/0022022111435097

Pek, J., \& Hoyle, R. H. (2016). On the (in)validity of tests of simple mediation: Threats and solutions. Social and Personality Psychology Compass, 10(3), 150-163. https://doi.org/10.1111/spc3.12237

Phinney, J. S., \& Devich-Navarro, M. (1997). Variations in bicultural identification among African American and Mexican American adolescents. Journal of Research on Adolescence, 7(1), 3-32. https://doi.org/10.1207/s15327795jra0701_2

Reid, D. W., Dalton, E. J., Laderoute, K., Doell, F. K., \& Nguyen, T. (2006). Therapeutically induced changes in couple identity: The role of we-ness and interpersonal processing in relationship satisfaction. Genetic, Social, and General Psychology Monographs, 132(3), 241-284. https://doi.org/10.3200/MONO.132.3.241-288

Rico, B., Kreider, R. M., \& Anderson, L. (2018, July). Growth in Interracial and Interethnic Married-Couple Households. U.S. Census Bureau. https://www.census.gov/library/stories/2018/07/interracial-marriages.html 
Rockquemore, K. A., \& Brunsma, D. L. (2002). Socially embedded identities: Theories, typologies, and processes of racial identity among Black/White biracials. The Sociological Quarterly, 43(3), 335-356. https://doi.org/10.1111/j.15338525.2002.tb00052.x

Rusbult, C. E. (1980). Commitment and satisfaction in romantic associations: A test of the investment model. Journal of Experimental Social Psychology, 16(2), 172-186. https://doi.org/10.1016/0022-1031(80)90007-4

Rusbult, C. E., Martz, J. M., \& Agnew, C. R. (1998). The Investment Model Scale: Measuring commitment level, satisfaction level, quality of alternatives, and investment size. Personal Relationships, 5(4), 357-391. https://doi:10.1111/j.1475-6811.1998.tb00177.x

Rusbult, C. E., \& Van Lange, P. A. M. (2008). Why we need interdependence theory. Social and Personality Psychology Compass, 2(5), 2049-2070. https://doi.org/10.1111/j.17519004.2008.00147.x

Schwartz, S. J., Zamboanga, B. L., Rodriguez, L., \& Wang, S. C. (2007). The structure of cultural identity in an ethnically diverse sample of emerging adults. Basic and Applied Social Psychology, 29(2), 159-173. https://doi.org/10.1080/01973530701332229

Seshadri, G., \& Knudson-Martin, C. (2013). How couples manage interracial and intercultural differences: Implications for clinical practice. Journal of Marital and Family Therapy, 39(1), 43-58. https://doi.org/10.1111/j.1752-0606.2011.00262.x

Skinner, A. L., \& Hudac, C. M. (2017). “Yuck, you disgust me!” Affective bias against interracial couples. Journal of Experimental Social Psychology, 68, 68-77. https://doi.org/10.1016/j.jesp.2016.05.008 
Skinner, A. L., \& Rae, J. R. (2019). A robust bias against interracial couples among White and Black respondents, relative to multiracial respondents. Social Psychological and Personality Science, 10(6), 823-831. https://doi.org/10.1177/1948550618783713

Smith, T. B., \& Silva, L. (2011). Ethnic identity and personal well-being of people of color: A meta-analysis. Journal of Counseling Psychology, 58(1), 42-60. https://doi.org/10.1037/a0021528.

Sprecher, S., \& Felmlee, D. (1992). The influence of parents and friends on the quality and stability of romantic relationships: A three-wave longitudinal investigation. Journal of Marriage and the Family, 54(4), 888-900. https://doi.org/10.2307/353170

Statistics Canada (2011). Mixed unions in Canada - National Household Survey (catalogue no. 99-010-X2011003). Statistics Canada. https://www12.statcan.gc.ca/nhs-enm/2011/assa/99-010-x/99-010-x2011003_3-eng.cfm

Sternberg, R. J. (1986). A triangular theory of love. Psychological Review, 93(2), 119-135. https://doi.org/10.1037/0033-295X.93.2.119

Uskul, A. K., Lalonde, R. N., \& Konanur, S. (2011). The role of culture in intergenerational value discrepancies regarding intergroup dating. Journal of Cross-Cultural Psychology, 42(7), 1165-1178. https://doi.org/10.1177/0022022110383311

Valentine, D. (2018). Conceptions of mixed race and the politics of temporality [doctoral dissertation, Pennsylvania State University]. Electronic Theses and Dissertation for Graduate School. https://etda.libraries.psu.edu/catalog/15593dxv920.

Wardle, L. D. (1998). Loving v. Virginia and the Constitutional right to marry, 19701990. Howard Law Journal, 41(2), 289-348. 
Webster, G. D., Laurenceau, J. P., Smith, C. V., Mahaffey, A. L., Bryan, A. D., \& Brunell, A. B. (2015). An investment model of sociosexuality, relationship satisfaction, and commitment: Evidence from dating, engaged, and newlywed couples. Journal of Research in Personality, 55, 112-126. https://doi.org/10.1016/j.jrp.2015.02.004

West, A. L., Zhang, R., Yampolsky, M. A., \& Sasaki, J. Y. (2017). More than the sum of its parts: A transformative theory of biculturalism. Journal of Cross-Cultural Psychology, 48(7), 963-990. https://doi.org/10.1177/0022022117709533

Yampolsky, M. A., \& Amiot, C. E. (2016). Discrimination and multicultural identity configurations: The mediating role of stress. International Journal of Intercultural Relations, 55, 86-96. https://doi.org/10.1016/j.ijintrel.2016.09.002

Yampolsky, M. A., Amiot, C. E., \& de la Sablonnière, R. (2013). Multicultural identity integration and well-being: A qualitative exploration of variations in narrative coherence and multicultural identification. Frontiers in Psychology, 4(126), 1-15. https://doi.org/10.3389/fpsyg.2013.00126

Yampolsky, M. A., Amiot, C. E., \& de la Sablonnière, R. (2016). The Multicultural Identity Integration Scale (MULTIIS): Developing a comprehensive measure for configuring one’s multiple cultural identities within the self. Cultural Diversity and Ethnic Minority Psychology, 22(2), 166-184. https://doi.org/10.1037/cdp0000043 